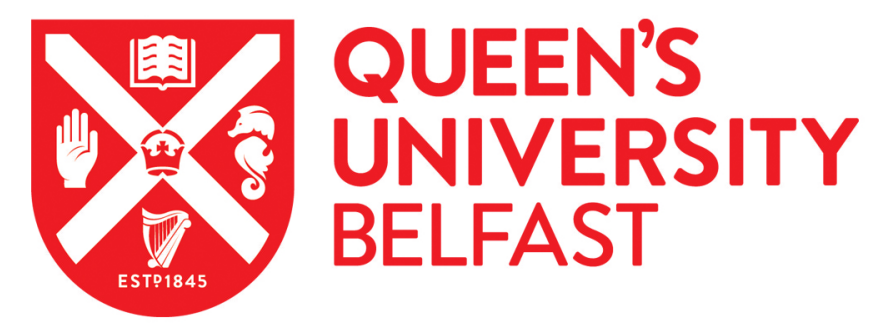

\title{
Microstructure evolution in CLAM steel under low cycle fatigue
}

Hu, X., Huang, L., Yan, W., Wang, W., Sha, W., Shan, Y., \& Yang, K. (2014). Microstructure evolution in CLAM steel under low cycle fatigue. Materials Science and Engineering A, 607, 356-359.

https://doi.org/10.1016/j.msea.2014.04.005

\section{Published in:}

Materials Science and Engineering A

\section{Document Version:}

Peer reviewed version

\section{Queen's University Belfast - Research Portal:}

Link to publication record in Queen's University Belfast Research Portal

\section{Publisher rights}

This is the author's version of a work that was accepted for publication in Materials Science and Engineering: A. Changes resulting from the publishing process, such as peer review, editing, corrections, structural formatting, and other quality control mechanisms may not be reflected in this document. Changes may have been made to this work since it was submitted for publication. A definitive version was subsequently published in Materials Science and Engineering: A, vol 607, 23 June 2014, DOI 10.1016/j.msea.2014.04.005.

\section{General rights}

Copyright for the publications made accessible via the Queen's University Belfast Research Portal is retained by the author(s) and / or other copyright owners and it is a condition of accessing these publications that users recognise and abide by the legal requirements associated with these rights.

Take down policy

The Research Portal is Queen's institutional repository that provides access to Queen's research output. Every effort has been made to ensure that content in the Research Portal does not infringe any person's rights, or applicable UK laws. If you discover content in the Research Portal that you believe breaches copyright or violates any law, please contact openaccess@qub.ac.uk. 


\title{
Microstructure evolution in CLAM steel under low cycle fatigue
}

\author{
Xue Hu ${ }^{1}$, Lixin Huang ${ }^{1,2}$, Wei Yan ${ }^{1}$, Wei Wang ${ }^{1}$, Wei Sha ${ }^{3}$, Yiyin Shan ${ }^{1}$, Ke Yang ${ }^{*}$ \\ 1. Institute of Metal Research, Chinese Academy of Sciences, 72 Wenhua Road, Shenyang 110016, China \\ 2. State Key Laboratory of Metastable Materials Science and Technology, Yanshan University, Qinhuangdao 066004, China \\ 3. School of Planning, Architecture \& Civil Engineering, Queen's University Belfast, Belfast BT9 5AG, UK \\ *Corresponding author. Tel.: +86 24 23971628; fax: +86 2423971628 \\ E-mail address: kyang@imr.ac.cn (Ke Yang)
}

\begin{abstract}
In the process of room-temperature low cycle fatigue, the China Low Activation Martensitic steel exhibits at the beginning cyclic hardening and then continuous cyclic softening. The grain size decreased and the martensitic lath transformed to cells/subgrains after the tests. The subgrains increase in size with increasing strain amplitude.
\end{abstract}

Keywords: electron microscopy; steel; fatigue; grain growth; grain refinement; dislocations

\section{Introduction}

The Reduced Activation Ferritic/Martensitic (RAFM) steels have been developed to be used as the candidate structural materials for the first wall and blanket in future nuclear fusion reactors ${ }^{[1,2]}$. In order to achieve the low activation and fast radioactive decay performances after irradiation, W (1-2 wt. \%) and Ta $\left(0.02-0.18\right.$ wt. \%) ${ }^{[3]}$ have been used in the RAFM steels to replace Mo and $\mathrm{Nb}$ that produce long-lived radionuclides. The structural materials for fusion reactors are generally under complex loading and neutron irradiation ${ }^{[4]}$ in an ultra-severe environment. The cyclic loading caused by the plasma operation $^{[5]}$ would probably induce a stress beyond the elastic limit of the steel. 
During the fatigue process, the microstructure evolution plays an important role on the cyclic softening behavior, fatigue properties and cyclic stress response.

The China Low Activation Martensitic (CLAM) steel has been developed using a modified composition of the 9 Cr-1.5WVTa RAFM steel ${ }^{[6,7,8]}$. The CLAM steel exhibits excellent mechanical properties, superior thermal stability and good irradiation-resistance. However, compared with other RAFM steels, for examples JLF- ${ }^{[5,9]}$, EUROFER97 ${ }^{[10-12]}$ and F82 $\mathrm{H}^{[12,13]}$, the fatigue data of the CLAM steel is limited in literature. In order to have better understanding of the CLAM steel, it is essential to investigate its microstructure evolution and fatigue failure behavior under cyclic strain and stress loading. Thus, investigations were undertaken in this study to characterize the effect of cyclic deformation on microstructure evolution of the CLAM steel at room temperature.

\section{Experimental details}

The chemical composition of the experimental CLAM steel is Fe-0.093C-8.96Cr-0.49Mn-0.16V-1.51W-0.14Ta-0.05Si (wt. \%). Material, fatigue test and microscopy details were given in [14] and the following supplements those details.

Low cycle fatigue (LCF) was performed with a servo fatigue machine (MTS 8801). The specimens were cycled using tension-compression loading under constant total strain amplitude control. The cyclic strain was measured by an extensometer. These fatigue tests were performed under fully reversed push-pull triangular wave. The cyclic life $\mathrm{N}_{\mathrm{f}}$ was defined to be the number of cycles 
corresponding to a $30 \%$ reduction in peak stress in tension from the value at half the total number of cycles. According to the Chinese national standard GB/T 15248-2008, the cyclic life $\mathrm{N}_{\mathrm{f}}$ can be defined as the number of cycles corresponding to a certain percent reduction in peak stress in tension from the value at the number of cycles representing half the separation life. So, the choice of $30 \%$ was somewhat arbitrary, but satisfied the standard. Other investigators had used $25 \%, 20 \%{ }^{[15]}$ and $10 \%{ }^{[10]}$.

During a fatigue test, when the stress in tension was much larger than $70 \%$ of the peak stress in tension at the stable part of the cyclic stress response curve, the LCF fatigue failure did not occur. In order to calculate the fatigue life, we could not stop the test at this point. The cyclic life $\mathrm{N}_{\mathrm{f}}$ can be defined as the number of cycles corresponding to a $30 \%$ reduction in peak stress in tension from the value at the stable part of the cyclic stress response curve. At this time, the specimen did not break to two parts. However, when we conducted the LCF test, we did not know when the fatigue failure would occur. We only could estimate that the fatigue failure point was around here. The test was allowed to continue. When the peak stress in tension equaled $30-40 \%$ of peak stress in tension from the value at the stable part of the cyclic stress response curve, we could be confident that the LCF life would be calculated accurately. The machine could be stopped. At this time, the specimen still did not break to two parts, but the crack on the surface could be observed clearly. Then, we used a hammer to break the failure specimens to two parts along the crack. 
When the cyclic stress decreased significantly during fatigue test, some micro-cracks were formed in matrix. After that, the cyclic stress mainly could promote the propagation and coalescence of the micro-cracks, and had little effect on microstructure evolution.

The samples used for optical microscope and scanning electron microscope observation were cut near the fracture surface. The slices used for the TEM observation were sampled adjacent to the metallographic specimen.

\section{Results and discussion}

Generally, the low cycle fatigue life of material ranges from more than 100 cycles to $10^{5}$ cycles. Under the strain amplitude of $0.25 \%$ to $2.0 \%$, the low cycle fatigue life of CLAM steel ranges from 21517 to 171 cycles. The strain amplitudes applied for the low cycle fatigue tests of CLAM steel are reasonable.

In our previous work ${ }^{[14]}$, it was observed that the low cycle fatigue properties of CLAM steel at room temperature obey the Coffin-Manson relationship. The fatigue parameters of the CLAM steel are similar to those of other conventional RAFM steels. The original data of strain and peak stress in tension during the first few cycles is shown in Table 1. It could be observed that when the target amplitude was $1.0 \%$, the peak stress in tension of the 3 rd cycle was $539.7 \mathrm{MPa}$, while the strain was only $0.985 \%$ and lower than that of the 1 st and 2 nd cycles. The specimen tested with the strain amplitude of $2.0 \%$ exhibited initial hardening at the 2 nd cycle, but the specimen tested with the strain amplitude of $1.0 \%$ exhibited initial hardening during the 1-3 cycles. The initial hardening 
behavior of CLAM steel during room-temperature LCF test was not thought to be affected by mechanical operation or not reaching the target strain. The cyclic hardening and the following cyclic softening are explained and discussed in a previous paper ${ }^{[14]}$.

Table 1 The actual value of strain and peak stress in tension during the first few cycles

\begin{tabular}{ccccc}
\hline $\begin{array}{c}\text { Target strain amplitude } \\
\%\end{array}$ & Cycle number & Strain & Plastic strain & $\begin{array}{c}\text { Stress } \\
\text { MPa }\end{array}$ \\
\hline & 1 & $\%$ & 0.068 & 327.2 \\
0.25 & 5 & 0.225 & 0.063 & 354.5 \\
& 10 & 0.235 & 0.066 & 365.7 \\
& 50 & 0.249 & 0.064 & 376.4 \\
& 100 & 0.249 & 0.064 & 376.2 \\
\hline \multirow{2}{*}{1.0} & 1 & 0.989 & 0.710 & 493.2 \\
& 2 & 0.986 & 0.687 & 533.3 \\
& 3 & 0.985 & 0.689 & 539.7 \\
& 4 & 0.996 & 0.705 & 539.7 \\
& 5 & 0.992 & 0.705 & 536.7 \\
\hline & 1 & 1.981 & 1.678 & 558.8 \\
& 2 & 1.974 & 1.652 & 589.4 \\
& 3 & 1.994 & 1.678 & 582.6 \\
& 4 & 1.985 & 1.674 & 575.4 \\
& 5 & 1.976 & 1.669 & 569.5 \\
\hline
\end{tabular}

\subsection{Prior austenite grain size and martensitic lath and subgrains}

During quenching, austenite transforms completely to martensite. Based on the low C-content, a laths structure is built. Within a prior austenite grain, the orientation of all the laths is almost the same. Consequently, the microstructure consists of domains of martensitic laths, and the boundaries of the domains are identical to the prior austenite grain boundaries. The average size of grains was $15-20 \mu \mathrm{m}$ before the LCF tests (Fig.1a). The grain evolved gradually during the cyclic deformation. The grain size was decreased to $10-15 \mu \mathrm{m}$ after the LCF tests 
with a strain amplitude of $0.25 \%$ (Fig. $1 b$ ). After the LCF tests with the strain amplitude of $2.0 \%$, a homogeneous microstructure was formed (Fig.1c). The grain size in this condition was about $5 \mu \mathrm{m}$. The purpose of Fig. 1 is to show grains and grain sizes. Optical micrographs are suitable for this purpose, to show the grain boundaries and the grains. Here what we need is not the high magnification or the high resolution, which are useful to show much finer features. On the other hand, SEM is usually not the best to show grain boundaries and the grains, because of how SEM works. See for example SEM images in [16], where the authors had to trace over the grain boundaries to highlight them.

The original TEM microstructure images, before fatigue, are shown in previous papers ${ }^{[8,14]}$. After the LCF test with the strain amplitude of $0.25 \%$, the width of martensitic lath increased significantly, and martensitic laths broke up into subgrains (Fig.2a, c.f. [14]). When the strain amplitude increased to $2.0 \%$, a number of polygon-shaped subgrains formed in the steel matrix (Fig.2b).

\subsection{Dislocation arrangement and precipitate distribution}

The cyclic deformation induced a large number of dislocations, which were tangled to form low-energy dislocation networks, and consequently to form the cell walls or subgrain boundaries. The movement of subgrain boundaries could be prevented by $\mathrm{M}_{23} \mathrm{C}_{6}$ carbides (Fig.2b), and the dislocation density in cells was low (Fig.3a) ${ }^{[17]}$. 
It was found that the $\mathrm{M}_{23} \mathrm{C}_{6}$ type carbides (60-200nm) lay along the subgrain boundaries (Fig.2b), martensitic lath boundaries (Fig.4) and prior austenite grain boundaries (Fig.2a) after room-temperature LCF failure. It can be observed from Fig.4 that the size and distribution of $\mathrm{M}_{23} \mathrm{C}_{6}$ carbides in the CLAM steel did not change obviously ${ }^{[8,14]}$. However, the fine MX type carbonitrides $(10-50 \mathrm{~nm})$ were formed within the subgrains to pin the dislocations (Fig.3b). In order to achieve low activation performance, the nitrogen content should be controlled to a very low level. In the CLAM steel, the nitrogen content was controlled to only 73 ppm, so the MX type carbonitrides mainly consisted of small size MC carbides. Because the mean atom weight of precipitates is larger than that of the matrix, the precipitates could be observed as bright particles in the back scattered electron (BSE) images. The BSE images of CLAM steel after fatigue tests showed that both the size and the distribution of $\mathrm{M}_{23} \mathrm{C}_{6}$ carbides and $\mathrm{MX}$ carbonitrides did not change obviously (Fig.5).

\section{Conclusions}

The microstructure of the heat-treated CLAM steel consisted of equiaxed grains $15-20 \mu \mathrm{m}$ in diameter. It evolved gradually during the LCF tests. After fatigue process, the major changes in microstructure of CLAM steel included (1) that the grain size decreased with strain amplitude, and (2) the formation of fatigue cells/subgrains. No visible changes in size and distribution of $\mathrm{M}_{23} \mathrm{C}_{6}$ carbides and MX carbonitrides were observed up to the strain amplitude of $2.0 \%$. 


\section{Acknowledgements}

This work was financially supported by funds from the ITER Program (No.2009GB109002) and Chinese Academy of Sciences Knowledge Innovation Program (KJCX2-YW-N35). It was carried out in cooperation with the FDS Team of Institute of Plasma Physics, Chinese Academy of Sciences.

\section{References}

[1] F. Abe, T. Noda, H. Araki, M. Okada. Journal of Nuclear Science and Technology 31 (1994) 279-292.

[2] E. Lucon, P. Benoit, P. Jacquet, E. Diegele, R. Lässer, A. Alamo et al. Fusion Engineering and Design 81 (2006) 917-923.

[3] V. Shankar, K. Mariappan, A. Nagesha, G. V. Prasad Reddy, R. Sandhya, M. D. Mathew et al. Fusion Engineering and Design 87 (2012) 318-324.

[4] G. R. Odette, M. J. Alinger, B. D. Wirth. Annual Review of Materials Research 38 (2008) 471-503.

[5] A. Nishimura, T. Nagasaka, N. Inoue, T. Muroga, C. Namba. Journal of Nuclear Materials 283-287 (2000) 677-680.

[6] J. Qiu, X. Ju, Y. Xin, S. Liu, B. Y. Wang. Journal of Nuclear Materials 411 (2011) 20-24.

[7] Q. Huang, J. Li, Y. Chen. Journal of Nuclear Materials 329-333 (2004) 268-272.

[8] X. Hu, L. Huang, W. Yan, W. Wang, W. Sha, Y. Shan et al. Materials Science and Engineering A 586 (2013) 253-258.

[9] H. Li, A. Nishimura, Z. Li, T. Nagasaka, T. Muroga. Fusion Engineering and Design 81 (2006) 241-245.

[10] P. Marmy, T. Kruml. Journal of Nuclear Materials 377 (2008) 52-58.

[11] N. V. Luzginova, J. Rensman, P. ten Pierick, J. B. J. Hegeman. Journal of Nuclear Materials 409 (2011) 153-155.

[12] M.-F. Maday. Fusion Engineering and Design 61-62 (2002) 665-670.

[13] J. F. Stubbins, D. S. Gelles. Journal of Nuclear Materials 233-237 (1996) 331-335.

[14] X. Hu, L. Huang, W. Wang, Z. Yang, W. Sha, W. Wang et al. Fusion Engineering and Design 88 (2013) 3050-3059.

[15] V. S. Srinivasan, R. Sandhya, K. Bhanu Sankara Rao, S. L. Mannan, K. S. Raghavan. International Journal of Fatigue 13 (1991) 471-478.

[16] W. Sha, A. Ye, S. Malinov, E. A. Wilson, Materials Science and Engineering A 536 (2012) 129-135.

[17] M. F. Giordana, P.-F. Giroux, I. Alvarez-Armas, M. Sauzay, A. Armas, T. Kruml. Materials Science and Engineering A 550 (2012) 103-111. 

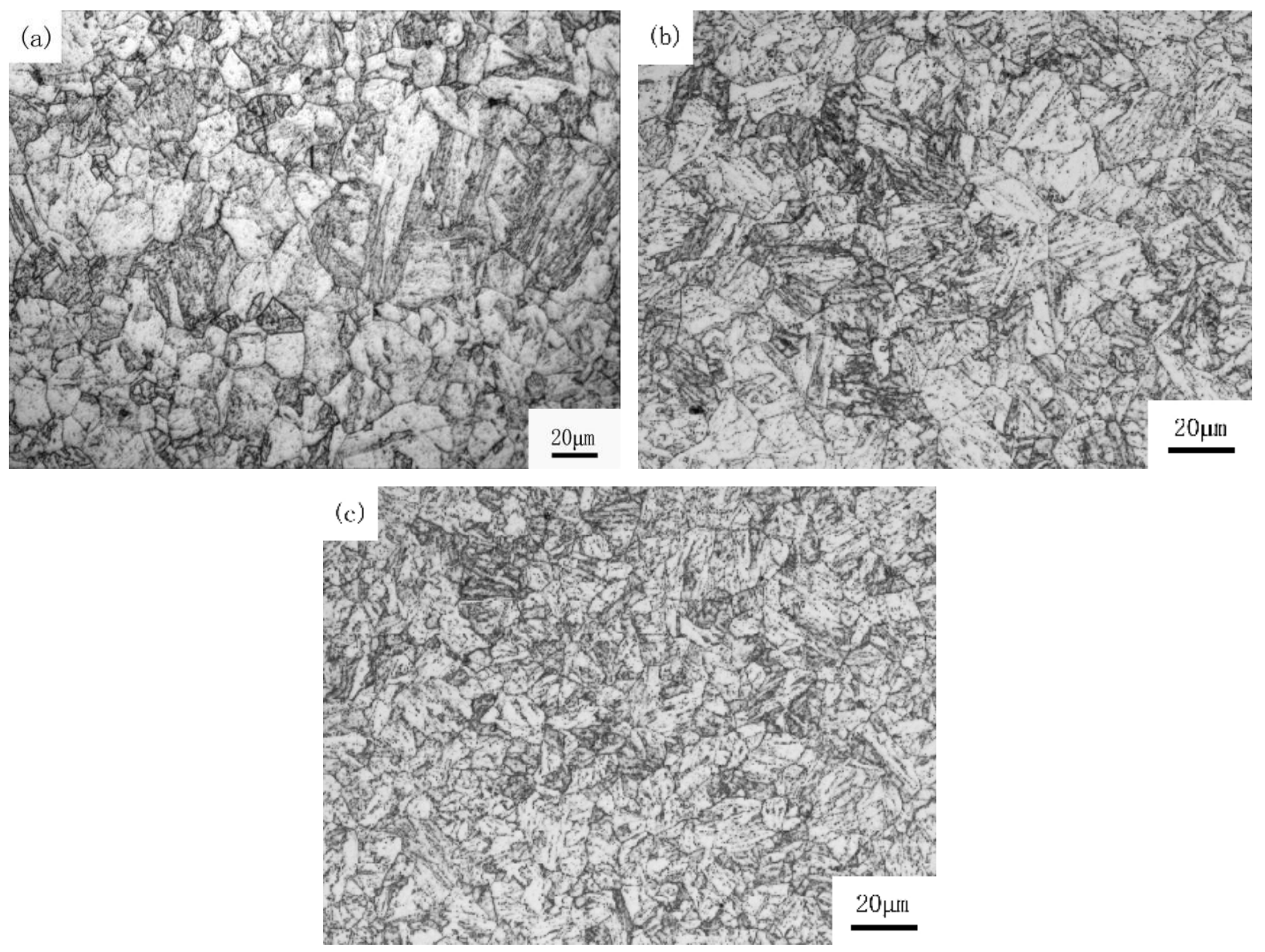

Fig.1 Optical micrographs of CLAM steel before and after LCF tests. (a) Heat-treated microstructure; (b) strain amplitude $0.25 \%, \mathrm{~N}=24658$; (c) strain amplitude $2.0 \%, \mathrm{~N}=190$. 

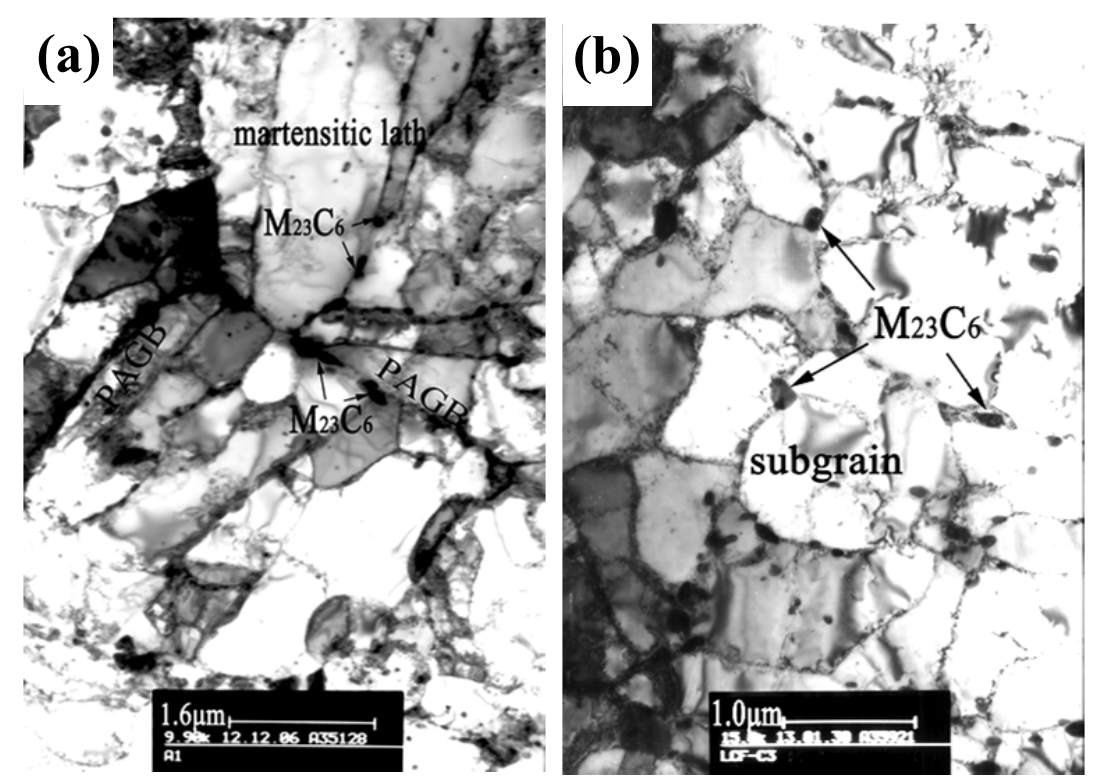

Fig.2 TEM micrographs after LCF tests. (a) Strain amplitude 0.25\%, N = 24658; (b) strain amplitude 2.0\%, N=190. 


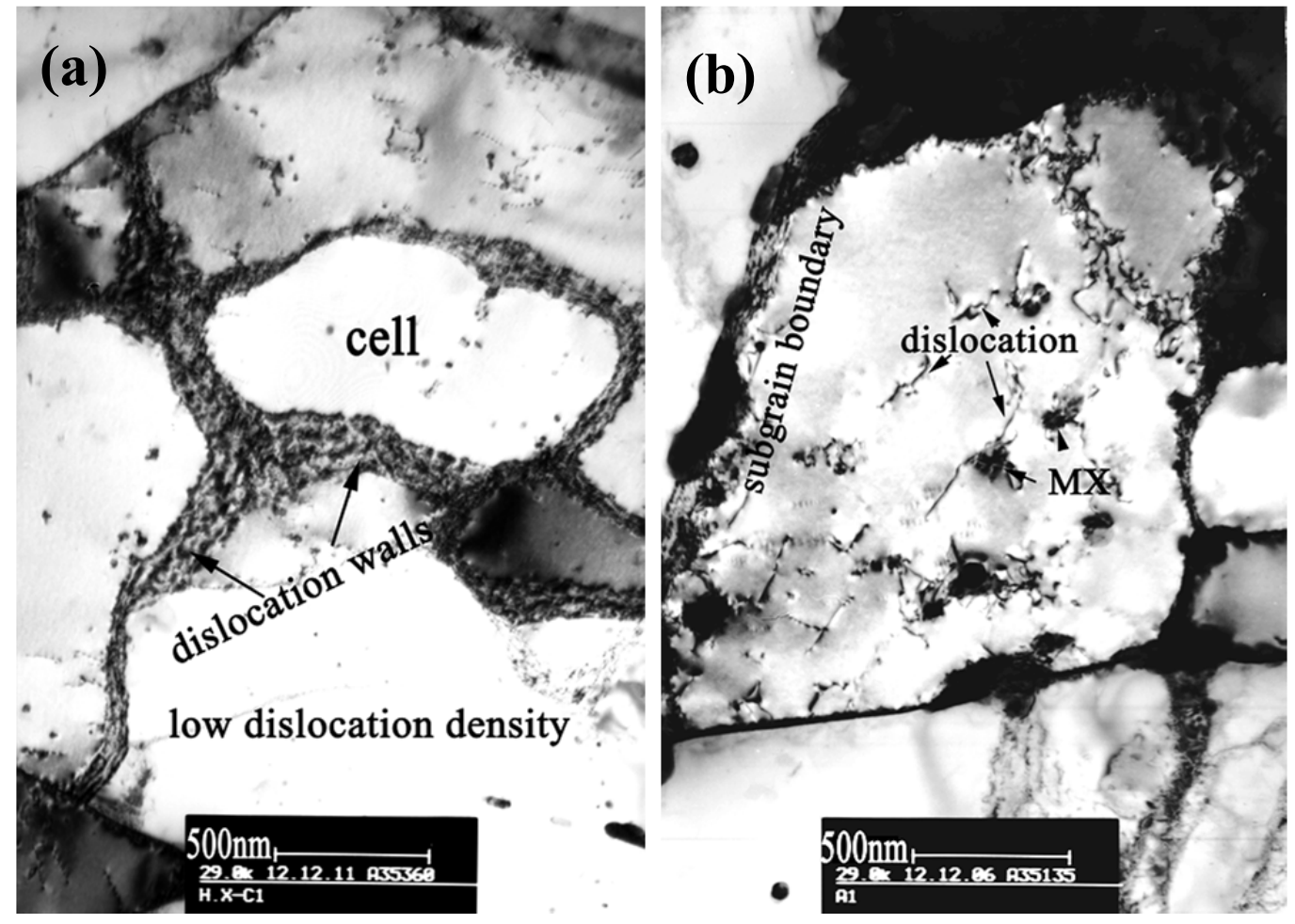

Fig.3 TEM micrographs of subgrains and fatigue cells in CLAM steel after fatigue failure. (a) Strain amplitude 1.6\%, $\mathrm{N}=239$; (b) strain amplitude $0.25 \%, \mathrm{~N}=24658$. 


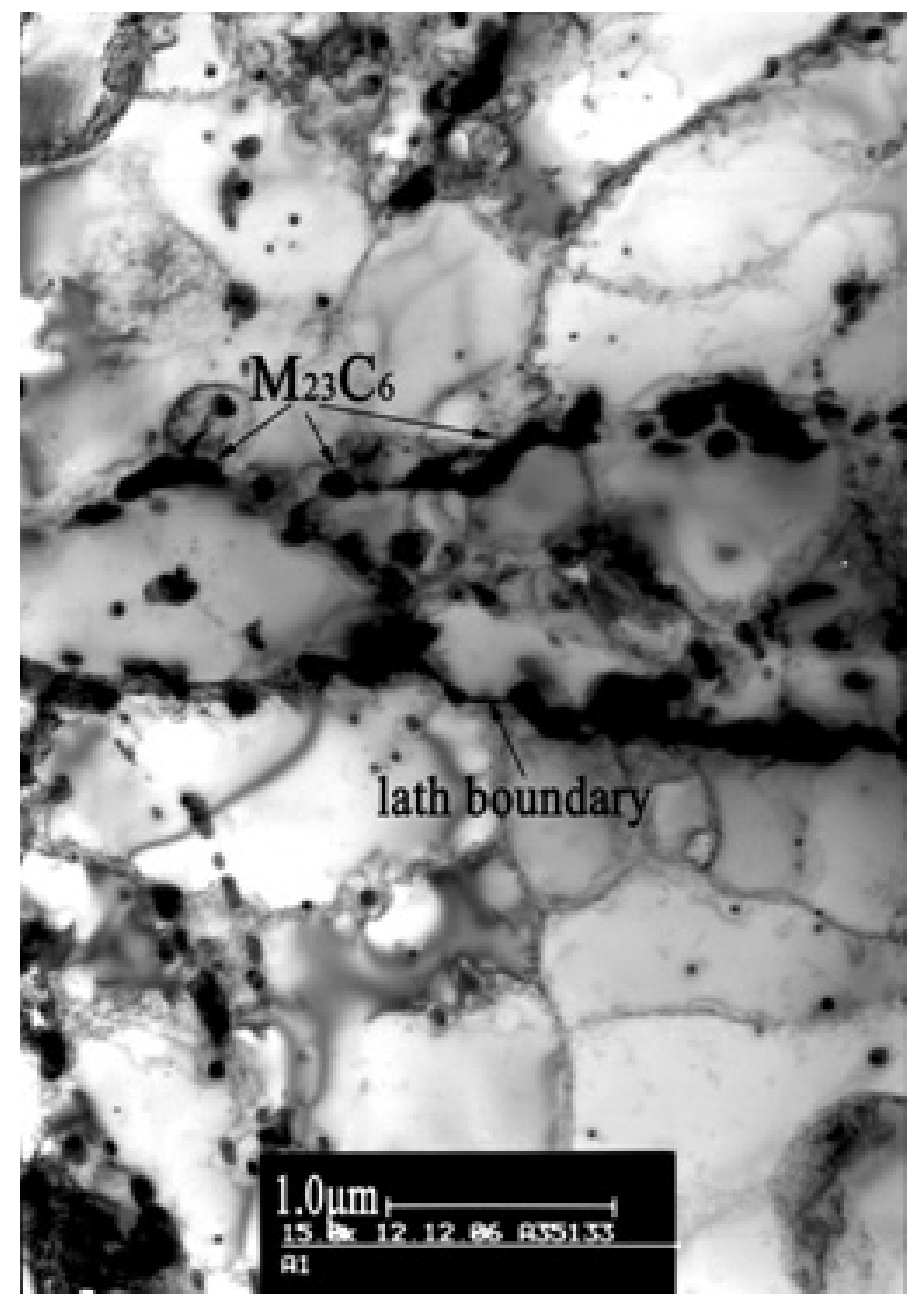

Fig.4 TEM micrograph of precipitates in CLAM steel after fatigue failure with a strain amplitude of $0.25 \%$ and a conatant strain rate of $6 \times 10^{-3} \mathrm{~s}^{-1}, \mathrm{~N}=\mathbf{2 4 6 5 8}$. 

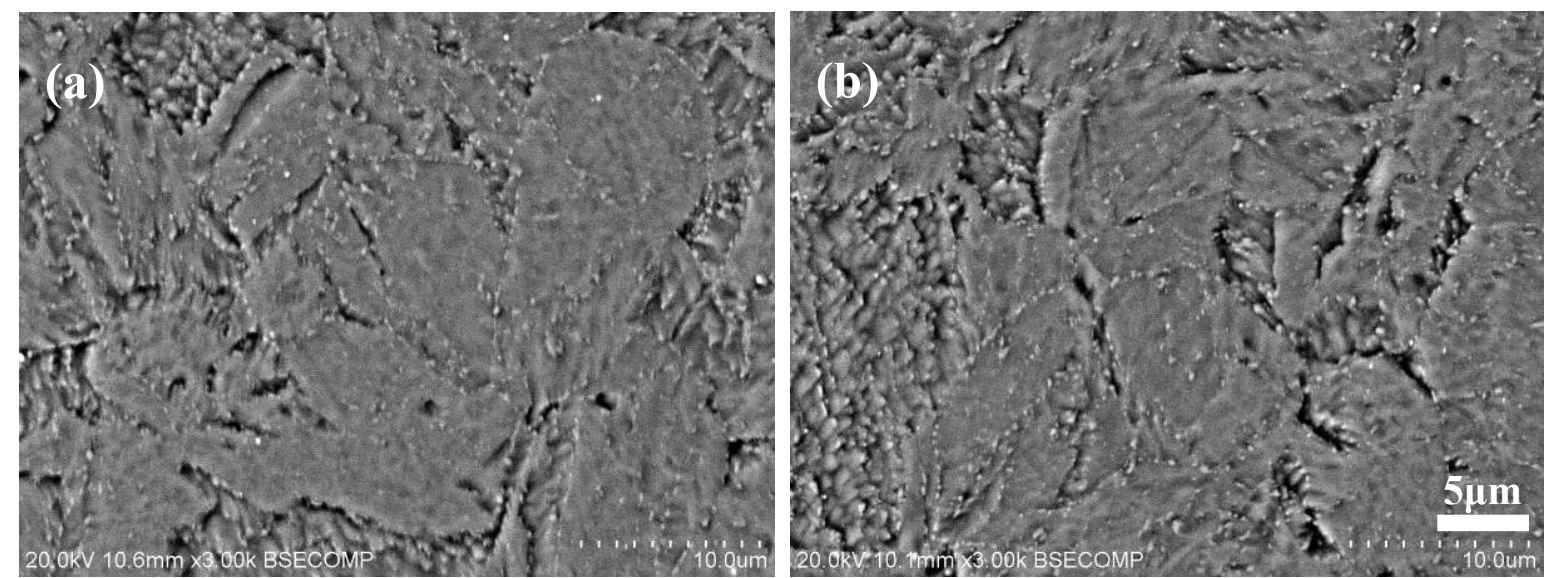

Fig.5 BSE micrographs precipitates in CLAM steel after fatigue failure. (a) Strain amplitude $0.25 \%, \mathrm{~N}=\mathbf{2 4 6 5 8}$; (b) strain amplitude $2.0 \%, \mathrm{~N}=190$. 